\title{
Téoros
}

Revue de recherche en tourisme

\section{Ne pas perdre le nord!}

\section{Charles Boulanger}

Volume 8, numéro 3, novembre 1989

Tourisme hivernal

URI : https://id.erudit.org/iderudit/1080313ar

DOI : https://doi.org/10.7202/1080313ar

Aller au sommaire du numéro

Éditeur(s)

Université du Québec à Montréal

ISSN

0712-8657 (imprimé)

1923-2705 (numérique)

Découvrir la revue

Citer cet article

Boulanger, C. (1989). Ne pas perdre le nord! Téoros, 8(3), 35-35.

https://doi.org/10.7202/1080313ar

Ce document est protégé par la loi sur le droit d'auteur. L'utilisation des services d'Érudit (y compris la reproduction) est assujettie à sa politique d'utilisation que vous pouvez consulter en ligne.

https://apropos.erudit.org/fr/usagers/politique-dutilisation/
Cet article est diffusé et préservé par Érudit.

Érudit est un consortium interuniversitaire sans but lucratif composé de l’Université de Montréal, l'Université Laval et l'Université du Québec à Montréal. Il a pour mission la promotion et la valorisation de la recherche. https://www.erudit.org/fr/ 


\section{Ne pas perdre

Lorsqu'on évoque la destination touristique européenne, on pense naturellement au soleil d'Espagne, aux montagnes suisses et bien entendu à la France pour des raisons sentimentales évidentes.

Mais de quelle Europe s'agit-il? La neige n'est qu'une réalité de hautes montagnes! Le littoral méditerraneen n'a rien à voir avec la péninsule gaspésienne! Montréal, ce n'est pas Paris!

Et pourtant de par la jeunesse de notre science du tourisme et pour des raisons culturelles, c'est souvent en Europe continentale francophone que notre communauté de professionnels puise son inspiration pour la planification du développement touristique.

Il existe cependant une autre Europe. Celle qui vit au rythme de nos quatre saisons. Où la mer, la forêt, l'hydro électricitécl' occupent une place prépondérante dans l'économie. L'Europe du nord formée de la Norvège, de la Suède et de la Finlande ressemble à l'est du Canada. Rappelons seulement ici quelques similitudes de la Suède et du Québec: dans ces deux contrées, l'agriculture ( $9 \%$ de la superficie suédoise) et la population sont concentrées au sud du pays. Le territoire forestier est immense et son nord est inclus dans la zone arctique. La population (8 300000 habitants) constitue un petit peuple dont la langue a peu de similitude avec les pays d'Europe au "sud'? ${ }^{4}$.

Stockholm (1 400000 habitants) comme Montréal, Helsinki (500 000 habitants) et Oslo (650 000 habitants) comme St-John et Québec sont par rapport à l'Europe ou à l'est de l'Amérique les 6 villes d'importance les plus nordiques.

Sur le plan touristique, on peut prétendre que notre problématique est aussi comparable: pensons à la brièveté des activites nautiques les plus populaires; à la concurrence des destinations soleil; à la

- Monsiaur Charlas Boulanger, Directeur gentefal, ATR Lana. diere: localisation des grands bassins de population, tous situés plus au sud, en Europe comme en Amérique; au problème de la rentabilite des infrastructures lie à de courtes saisons d'exploitation.

Ce questionnement sur notre "nordicité touristique" nous laisse froid! C'est normal sans jeu de mot. Notre manque d'intérêt à l'environnement nordique est historique et fondé sur nos origines septentrionales et notre humanité latine. Notre incompréhension de la nordicité est un problème constant d'occupation du pays: du scorbu de Monsieur Champlain a $1^{\dagger}$ absence actuelle de modeles de développement touristique nordique. L'adaptation architecturale qu'a dú subir l'habitation de pierre française, humide et froide, pour devenir la maison de bois québécois propre à nos rigoureux hivers illustre bien la créativité nécessaire à l'ếmergence d'un développement touristique original et rentable.

Notre mémoire collective a maintenu une vision négative du nord (et de ses habitants) dont la source est probablement antérieure à notre migration en Amérique alors que les vikings terrorisaient nos peuples "civilises"s" continentau ${ }^{(3)}$. Cette affirmation devrait faire l'objet d'une savante démonstration mais retenons ici que toute une série de raisons géographiques, historiques, linguistiques nous ont peu enclins à puiser à l'expérience touristique scandinave.

Qui peut au sein de notre intelligencia prétendre que nos interventions tiennent compte de notre nordicité? Et pourtant, en foresterie, il y a déjà un bon moment que l'on travaille sciemment avec les scandinaves.

Qu'enest-il du phenomène de la villégiature dans ces pays? Comment planifie-t=on l'excursionnisme péri-urbain? Quelle est leur portion de clientèle internationale et pour quels produits? De quelle façon est servile produit "grands espaces"? Dequelle façon est structurée la formation universitaire en tourisme? Autant de questions auxquelles bien peu d'intervenants québecois pourraient actuellement répondre.

Bref, nous devons reconnaître notre spécificité nordique non plus comme handicapou une opportunité passagère en marketing mais plutôt comme une réalité qui conditionne et conditionnera notre prospérite. Nous devons comme les secteurs primaire et secondaire, établir une franche collaboration avec nos partenaires scandinaves. Il existe dejà une association des villes nordiques, pourquoi pas une association plus étroite de nos universités.

Gilles Vigneault nous chante: "Mon pays ce n'est pas un pays, c'est l'hiver", la manifestation la plus évidente de notre nordicité.

Du ski originel d'Europe du Nord, nous avons fait au Mont Tremblant le ski alpin modeme qui, avec la remontée mécanique,

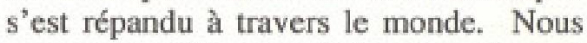
avons inventé le sport de la motoneige qui actuellement connaît ses premiers balbutiements en Finlande. Le pays forge ses habitants et ses institutions. Partageons nos rêves avec ceux dont les nuits sont froides et le feu nourri de bouleaux ${ }^{(4)}$.

\section{Notes explicatives}

(1) Dans rordre le Canada, la Norwage et la Subde sont par d'habiant les plus grands consommoteurs d'electricite au moncte.

(2) En Suede, la langue seconde apprise a l'ecole est l'angle's:

(3) En l'an 886, une armada de 700 drakkars, montés par 40000 hommes fit route sur la Seine vers Paris.

14) Le bouleau est le feuillu au bois dur le plus nordique. De plus, sa repartitiondansl'hemisphère nord est circumpolaire. 